\title{
The EAPC/PfP as an Instrument to Combat Global Terrorism
}

by Michel Hess*

There is no multilateral security framework whose mandate has not been reexamined - and, in many cases, fundamentally redefined - in the aftermath of 11 September 2001. ${ }^{1}$ The search for an effective response at a multilateral level to global terrorist networks and the organized crime structures supporting these networks mirrored the extensive national measures and bilateral efforts undertaken to enhance homeland security. While it has been fashionable in academic circles to refer to the blurring of the distinction between national and international security, the magnitude and the nature of the terrorist attacks delivered the most convincing argument in favor of merging and intensifying the coordination between domestic intelligence, foreign policy, and defense policy.

The invocation of Article $\mathrm{V}$ of the North Atlantic Treaty was the swiftest multilateral response to the terrorist attacks on the United States masterminded by the al Qaeda network. On 12 September 2001, the Euro-Atlantic Partnership Council (EAPC) adopted a package of measures designed to combat the scourge of terrorism. Within a week of the terrorist attacks, more than thirty countries had offered disaster relief assistance to the United States through the Euro-Atlantic Disaster Relief Coordination Center. By December 2001, the EAPC had adopted the new EAPC Action Plan for 2002-2004 based on innovative counter-terrorist approaches suggested in a joint Finnish-Swedish "food-for-thought" paper.2 One year later, at the Prague Summit, the EAPC member states endorsed a Partnership Action Plan against Terrorism (PAPT), including practical mechanisms and an action plan ranging from intensified consultation and information sharing and increased prepared-

\footnotetext{
* Dr. Michel Hess is Chief of Section, Service for Strategic Analysis and Prevention, Swiss Federal Department of Justice and Police, Bern. Formerly, he served as Manager of the International Relations and Security Network (ISN), Swiss Federal Institute of Technology, Zurich, and as Academic Director at the School for International Training \& World Learning, Brattleboro, Vermont (U.S.).

${ }^{1}$ See, for example, the excellent document collection in the Romanian Journal of International Affairs 13:1-2 (2002) dealing with the "Bucharest OSCE Ministerial Declaration," the OSCE Declaration of the Bishkek Conference, and the reinvigorated UN General Assembly Declaration on Measures to Eliminate Terrorism of 1994 and the Convention for the Suppression of the Financing of Terrorism of 1999, as well as UN Security Council Resolution 1373.

2 For the original text of the paper by Sweden and Finland, "Partnership 2002 and Beyond," see http://www.utrikes.regeringen.se.
} 
ness to combat terrorism to consequence management (civil emergency planning) and technical assistance (trust funds, mentoring programs). ${ }^{3}$

The Action Plan's measures to fight terrorism have been supported by a series of tangible activities and events to date, most notably three EAPC/PfP seminars on the fight against terrorism held in Warsaw, Yerevan, and Baku. I participated in these workshops, and would suggest that it is time to have a fresh look at the Partnership for Peace (PfP) framework along the same lines, as was the case with the Alliance in the early 1990s. ${ }^{4}$ A partial answer may have already been provided with the PAPT, yet it is vital to take a critical look at recent developments, establish an inventory of what has been accomplished, and identify the major directions and policy options available beyond simply muddling through. This paper concludes with a recommendation regarding the extent to which the EAPC/PfP framework can and should continue to be used as a meaningful and viable instrument to contribute to Euro-Atlantic security in an era of asymmetric threats.

\section{Flexibility, Pragmatism, Inclusiveness}

With the presentation of the PfP framework document in January 1994, the North Atlantic Council resolved its rather embarrassing dilemma of not being able to offer full treaty membership to Central and Eastern European countries. ${ }^{5}$ Little did the Council know back then that an instrument originally conceived as an "exit option" would become the Alliance's most active, versatile, and flexible framework of cooperation. PfP engagement tailored bilaterally to countryspecific interests and needs responded ex post facto to altered geopolitical realities, much in the same way that the Alliance would respond to terrorism with PAPT ten years later. However, it also proactively ushered in a sea change in the Alliance's security paradigm. This shift was most markedly demonstrated with the introduction of the principle of transparency in defense planning and budgeting processes, and the Partnership Planning and Review Process (PARP).

\footnotetext{
${ }^{3}$ For the original texts of the Partnership Action Plan Against Terrorism (PAPT, 22 November 2002) and the EAPC Action Plan 2002-2004 (7 December 2001), see http://www.nato.int/docu/basictxt/b021122e.htm and http://www.nato.int/docu/pr/2001/p01-165e.htm respectively. The major chapters in the PAPT include: intensifying consultations and information sharing; enhancing preparedness to combat terrorism; impeding the support of terrorist groups; enhancing capabilities to contribute to consequence management; and assisting partners" efforts against terrorism. The Action Plan includes - in Section II, dealing with the long-term program for consultation and cooperation - a substantive element on the international fight against terrorism.

${ }^{4}$ See, for example, Ronald Asmus, et al., "Building a New NATO," Foreign Affairs (September/October 1993); Ole Diehl, "Opening NATO to Eastern Europe," World Today 49:2 (December 1993); Charles Glaser, "Why NATO Is Still Best," International Security 18:1 (Summer 1993); Jeffrey Simon, "Does Eastern Europe Belong in NATO?" Orbis 37:1 (Winter 1993).

${ }^{5}$ See the NATO online library at http://www.nato.int/docu/basictxt/b940110b.htm for the original version of the text.
} 
While the PfP seemed at face value something of a suboptimal, legally non-binding "waiting room," the enhanced and more operational PfP was introduced - with the development of practical areas of cooperation and individual partnership programs - as one of the most successful capacity-building and confidence and security-building instruments that the Euro-Atlantic region has seen in recent memory. When the dismantling of the Warsaw Pact seemingly undermined the Alliance's raison d'être, the notion that NATO must "go outof-area or out of business" presented itself as a convenient metaphor. PfP was a hands-on solution for the need to go "out-of-area" politically without having to address outstanding legal issues. PfP testified to the continued existence of an Alliance that had always rested on both a military and a political pillar - that was, in short, a community of values. NATO did go "out-of-area" militarily a couple of years later, but in a much more direct fashion than could originally have been anticipated. The wars in former Yugoslavia carried NATO across the threshold towards intervention in the period 1995-1999. In addition, military intervention for humanitarian purposes without a UN mandate was declared as both necessary and justified. NATO realized that the major challenges to European stability and security started where the territorially-bound definition of the legal applicability of the Alliance's Article V provisions ended. The key questions, therefore, that soon emerged were much more complex and farreaching: which "area," which "Europe," and which "business"?

In this period of NATO's first military interventions beyond treaty territory in South Eastern Europe, PfP operated as the primary mechanism for military support and political engagement and stabilization in the areas adjacent to former Yugoslavia. This agent of change and vehicle for capacity-building ultimately enabled these countries to submit viable candidacies for NATO membership in two successive rounds. However, NATO's political outreach through the PfP beyond the Black and Caspian Seas also allowed for a wide range of individually-tailored participation and consultation, which would ultimately (and inadvertently) prepare the diplomatic and political ground for NATO military engagement beyond Eurasia in the global fight against terrorism.

Now that the Membership Action Plan (MAP) countries are on their way to joining the Alliance as full treaty members in the wake of the Prague Summit, PfP is undergoing a fundamental redefinition in two strategic directions. With regard to membership, the greater heterogeneity between the remaining five neutral and technologically-advanced Western European countries and the five Central Asian, three Caucasian, three Eastern European, and three South Eastern European countries will have an impact on both the content and the process of the Partnership. The fulfillment of MAP aspirations means that the "missing link" of political and socio-economic middle-range PfP participants will present considerable programmatic challenges to the remaining partners. With regard to the fundamental purpose of the Partnership, an updating and streamlining of basic documents, procedures, and activities has become 
essential, especially in light of the changed crisis management and anti-terrorism capacity needs. Establishing practical operative linkages between such a wide spectrum of partners will be key for the meaningful continuation of the PfP.

\section{Requirements and Relevant Instruments}

With the second round of robust NATO enlargement undertaken at the Prague Summit, and precursory signals for further steps at Oberammergau and Reykjavik, one could have concluded that the PfP would wither away without leaving any significant vacuum behind, having accomplished its primary mission: the military-technical and political-diplomatic preparation of the MAP countries for full NATO membership. There are three distinct reasons why PfP has definitely not withered away, but rather has gained a new pragmatic purpose and operational presence testifying to its versatility as a security policy instrument.

First, the Prague Summit made it clear that the Alliance would henceforth operate with a truly global military projection capability, as evidenced by the Iraq war, the preparations for guaranteeing the safety of Kabul, and the support of American and British troops in occupied Iraq. By taking over the leadership of the International Security Assistance Force (ISAF) in Afghanistan, NATO has indeed not only gone "out-of-area" politically, but has also intervened militarily for the first time outside of the Euro-Atlantic region as defined by PfP membership. Romania and Bulgaria are strategically key for the provision of landing rights, air bases, air space, and coastal rights on the Black Sea. Along with options provided by Poland and Hungary, NATO can now examine new deployment and troop-stationing concepts that push the perimeter of Europe's geopolitical sphere of influence towards Central Asia and the Middle East. Militarily and politically, the "new Europe" emerging out of PfP has therefore played an innovative role that goes well beyond the impact of the support provided for the U.S. intervention in Iraq.

A landmark of the first and second rounds of enlargement, however, was the extended political role that the Alliance would also fulfill. This role was a consequence of the geographic expansion of the legal applicability of automatic military assistance clauses to former PfP countries which - in spite of significant advances in interoperability - had not yet entirely completed the full range of treaty membership requirements. Capacity-building rather than legal conditionality is a pragmatic approach that NATO adopted as a lesson learned at Prague directly from the overwhelmingly positive PfP experience. These developments essentially confirmed the viability of a two-pronged strategy in which PfP would continue to play an essential role that dovetails nicely with NATO tradition: providing operational military deployment wherever needed, as defined by the North Atlantic Council (Madrid Summit), and political con- 
sultation and information sharing with those PfP countries not on the NATO membership track. ${ }^{6}$ In the first case, the PfP remains the only consultative framework, especially for deployments in areas from which asymmetric threats, terrorism, and the proliferation of weapons of mass destruction emanate. In the second case, there is at present no alternative security policy link to the five Central Asian and three South Caucasian countries that are at the operational forefront in the combat against global terrorism.

Second, let us remember that, without the established PfP channels linking the Alliance to Central Asian and South Caucasian partner countries, the international response against global terrorism would not have achieved the level of immediacy and efficiency it did in the aftermath of September 11. Territories and assets in those regions were made available to the international coalition; in some instances, full-fledged base and landing rights were granted. In the absence of any other mechanism for legal engagement, it is clear that the Alliance's only feasible option with regard to the geo-strategically sensitive regions of the South Caucasus and Central Asia remains the PfP process. Having accomplished the job of stabilizing Central and South Eastern Europe in the 1990s, the PfP was not only redefined to address the specific circumstances and requirements of the remaining PfP countries, but also to confront the new asymmetric security challenges within the possibilities presented by the EAPC/PfP format and mechanisms. Without the PfP process and network of operational contacts, further enhancements of interoperability and border management, and counter-terrorism cooperation in general, would simply become impracticable.

A third reason for the continuing vitality of the process can be found in the very efforts undertaken by the remaining partners to maintain the relevance and activity of the EAPC/PfP through a full range of measures in conformity with the PAPT and EAPC Action Plan. ${ }^{7}$ Especially for some of the neutral Western European partner countries, the EAPC/PfP is one of the very few cooperative security frameworks in which they can participate on an la la carte basis. It is therefore in their own national interests to continue to maintain an active

\footnotetext{
${ }^{6}$ The discussion of who is on a membership track and who is not is, of course, controversial. For simplicity's sake one could argue that the GUUAM group (Georgia, Uzbekistan, Ukraine, Azerbaijan, Moldova) is more inclined towards a NATO rapprochement than are the signatories of the Collective Security Treaty signed at Dushanbe, Tajikistan on 28 April 2003 (Armenia, Belarus, Kazakhstan, Kyrgyzstan, Tajikistan, Russia), which formally split the Commonwealth of Independent States (CIS) into a pro-NATO and a pro-Russian camp. Of the CIS countries, only Georgia and Azerbaijan have taken overt pronouncements and actions regarding the NATO membership question. None of the neutral European countries (Switzerland, Sweden, Austria, Ireland, Finland) want to join NATO. There is a reasonable chance that Bosnia-Herzegovina and Serbia and Montenegro will join the EAPC/PfP process soon after overcoming certain outstanding issues.

${ }^{7}$ In the case of Switzerland, these PAPT-relevant contributions include, for example: border control and management, security sector reform, terrorism financing, cyber crime, information and computer security, civil-military cooperation, and civil emergency planning.
} 
role, even though the PfP clearly will no longer incorporate partner countries that are, on the whole, at the same level of foreign and security policy priority as were the Central and Eastern European MAP countries. The high-quality contributions made by the neutral partners may well be refocused in the context of a PAPT implementation effort, but they will continue to be relevant also for the MAP countries, which will have access to more significant programs open specifically to NATO member states.

Beyond the initial momentum, though, much will depend on the degree to which Western European PfP countries are willing to make an honest effort at reaching out to Caucasian and Central Asian partners in the process and redirecting and focusing the resources available towards a more limited range of partnerships without immediately apparent benefits. At the same time, much will also depend on the political willingness of Caucasian and Central Asian partners to step up their commitment to active engagement in the PfP process and to take advantage of the opportunities presented by the EAPC/PfP format. A number of domestic, regional, and geopolitical obstacles may well impede engagement at the level and intensity of the activities conducted in the late 1990s with Central and Eastern European partners. As long as the PfP is not perceived as being directed against Russian regional interests - by all parties concerned - there is no reason to impute a quid pro quo to either membership in the Dushanbe Collective Security Treaty or an acceleration of PfP efforts. For instance, active participation by Armenia (joint PfP training exercise "Cooperative Best Effort 2003") and Tajikistan (Partnership work program) in the PfP are clear examples that the two are not mutually exclusive.

These three factors may explain to a significant extent the momentum that the PfP gained in light of the global struggle against terrorism. This momentum is most clearly documented by NATO's three-pronged partnership strategy: individual partnership programs, regional and functional cooperation, and the PAPT. In contrast to formal legal arrangements, the PfP's comparative advantage continues to rest with the enormous flexibility it has afforded to NATO to define special and individual cooperative activities tailored to the specific national and regional circumstances of a partner country, to foster greater regional and functional work, and to develop PAPT as an instrument that complements rather than duplicates the work done by other organizations.

\section{Comparative Advantages and Liabilities}

Any analysis of core competencies is intricately tied to an honest assessment of limitations and parameters. What can EAPC/PfP do against global terrorism, and what can it not do? First and above all, EAPC/PfP is not an international police instrument akin to Interpol, designed for the exchange of classified law enforcement information between national intelligence services. There are other better, more operative channels for the exchange of information on terrorist and 
extremist groups and organized crime networks. At the same time, in such a case the open format of EAPC/PfP exchanges would jeopardize the very goals that they were intended to achieve. The action plan items listed under section 16.1 ("Intensify Consultations and Information Sharing") of the PAPT, notably the EAPC/PfP intelligence liaison unit (ILU), should not be looked at from an operative law enforcement perspective. Here the distinction between operativetactical and strategic-political intelligence is essential.

Most of the pertinent intelligence information is exchanged on a bilateral basis, or in very clearly defined small settings (Middle European Conference, Club of Berne, Interpol). What the EAPC/PfP's comparative advantage is in this field is clearly the capacity to bring civilian intelligence and military actors together for the exchange of declassified yet confidential strategic-political information on the full range of long-term terrorist threat scenarios and their linkages to organized crime. An exchange of this type of national information at a multinational level is of immense benefit to all civilian and military actors working on homeland security, and would also take advantage of the unique qualities presented by the EAPC/PfP format. It goes without saying that asymmetric threats require a joint practical civil-military response; this is precisely where the EAPC/PfP can step in to enhance cooperation between established diplomatic-military PfP channels and other state actors, notably domestic security services, law enforcement, and emergency services.

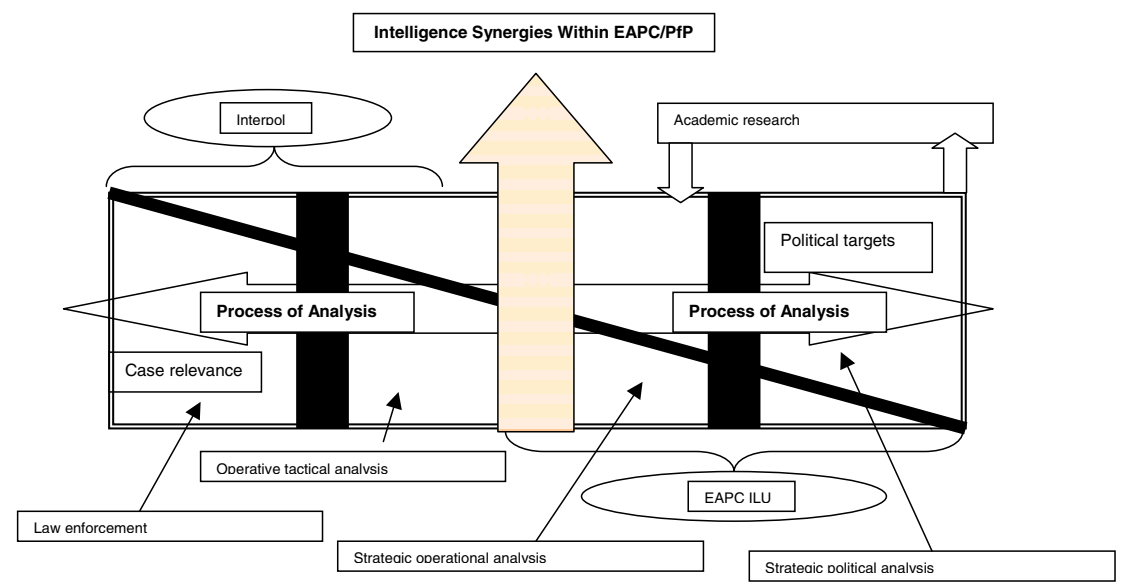

Second, an important working principle within EAPC/PfP is self-differentiation. This is the basis on which meaningful participation for a wide variety of EAPC member states, ranging from Switzerland to Turkmenistan, has become possible. The implications of this principle are two-fold. On the one hand, any movement toward strengthening the legal quality of the PfP frame- 
work, such as "partnership-plus," should be resisted in favor of the benefits of a flexible array of counter-terrorist instruments within EAPC/PfP, which are also compatible with national legislation. On the other hand, measures for combating terrorism have significant politically sensitive ramifications for the fields of defense and security sector reform, force planning, information exchange about forces, and training and exercises. It is important to reiterate that these measures should not be equated with a value judgment on a participating member state's domestic policies vis-à-vis democratic and parliamentary oversight over armed forces, etc.

The PAPT package that has been advanced to improve border controls and the preparedness of member states for combating terrorism indicates both desirable directions for domestic reforms and potential forms of assistance, which can be provided "upon request" (Article 9). With the PAPT, the EAPC/PfP offers a broad menu of instruments that can be expanded where needed. Most importantly, the PAPT is also open on a case-by-case basis to Mediterranean Dialogue partner countries, provides for consultations with the UN and the OSCE, and takes a long-term comprehensive approach to the fight against terrorism.

Clear liabilities of the PAPT instrument, however, can be discovered with respect to its ownership, resources, and regional conflicts and tensions, which impede its effective implementation. In order to address these issues, PAPT Article 14 stipulated specifically that EAPC member states would continue to promote regional cooperation initiatives to combat terrorism. Article 16.5 also mentioned the establishment of PfP trust funds to assist individual member states in specific efforts against terrorism, pursuant to the consolidated report on the comprehensive review of the EAPC/PfP. It is clear that these shortcomings are symptomatic of the novelty of the instrument. Evaluation efforts that are under way at present will result in the PAPT taking on a more rigorous form. The key is to make practical use of the document in order to be able to detect further shortcomings in time for the next EAPC Summit, to be held in three years.

\section{Recommendations for the Road Ahead}

Combating global terrorism and organized crime is an overwhelmingly complex long-term endeavor that demands multifaceted tools and approaches at both the national and multi-national level. The root causes of these phenomena are more deeply anchored than the mere logistics and financing that support them. At the national level, homeland security now involves decisions that cut across various organizational structures, such as ministries of finance, justice, defense, foreign affairs, and a diversity of legal frameworks.

The EAPC/PfP's core competencies are useful in addressing global terrorism in ways that are complementary to individual national initiatives. The 
fact that the primary nature of EAPC/PfP is a partnership and not a collective defense treaty is a major asset in the formulation of preventive counter-terrorism instruments that are tailored to local and regional circumstances and needs. The fact that the EAPC/PfP holds the protection and promotion of fundamental freedoms and human rights and the rule of law to be not just an overarching goal, but also a fundamental vehicle for combating terrorism (Article 4), testifies to the values that serve as a foundation to any effective preventive tools. The EAPC/PfP's comparative assets will be most useful when applied in the following areas:

- First, given that the sharing of sensitive operational and tactical intelligence is impossible within EAPC/PfP, the adoption of a secure platform and forum (either open-source or password-protected or both) for the exchange of best practices in counter-terrorism in the Euro-Atlantic area between civilian and military actors is of paramount importance. Such an exchange would not only establish a much-needed inventory of national measures, but would also put up for discussion the ways and means of how to best foster cooperative relations between EAPC member states in terms of formulating assistance programs and training and equipping personnel.

- Second, EAPC/PfP tools and activities urgently need to be reexamined from the ground up in order to give priority to counter-terrorist programs, including civil-military cooperation, civil emergency planning, and border management training.

- Third, the institutional mechanisms available within the EAPC/PfP, such as trust funds and weapons of mass destruction and disaster response coordination centers need to be operationalized more broadly.

In the latter two instances, it is clear that the issue of national "ownership" will come up in a most concrete way.

If deeds and tangible gestures follow counter-terrorist policies and words, supporting Southern Caucasus and Central Asian PfP partners in their efforts to curb terrorism will gain an added priority. Given the international coalition activities in Iraq and Afghanistan, the PfP will again have a stabilization role to fill in the areas bordering sites of military intervention, as was the case in the Balkans in the 1990s.

The nature, purpose, and meaning of PfP activities have been fundamentally changed by, inter alia, the multilateral response against terrorism, the process of NATO enlargement, NATO's relations with the European Union's ESDP, and the diffuse and uncertain geo-strategic rapprochement between NATO, the United States, and Russia. It is a lucky coincidence that the postPrague composition of the EAPC/PfP is geographically coterminous with the functional counter-terrorism requirements and operational needs that have 
emerged since 11 September 2001 in Central Asia and the Middle East. It would be a costly mistake not to take advantage of this unique constellation of abilities and the confidence-building capital that has been accumulated over close to ten years of PfP exercises and education and training activities. It would also be paradoxical to confront the EAPC region with a post-Prague cleavage of Alliance membership winners and losers, particularly as the most dramatic and convincing calls for political and military engagement now point towards Central Asia and the Caucasus. 


\section{Bibliography}

Asmus, Ronald. "Building a New NATO." Foreign Affairs (1993).

Diehl, Ole. "Opening NATO to Eastern Europe." World Today 49, no. 2 (1993).

Glaser, Charles. "Why NATO Is Still Best." International Security 18, no. 1 (1993).

Simon, Jeffrey. "Does Eastern Europe Belong in NATO?" Orbis 37, no. 1 (1993). 